\title{
Association of Door-to-Balloon Time and Mortality in Patients $\geq 65$ Years With ST-Elevation Myocardial Infarction Undergoing Primary Percutaneous Coronary Intervention
}

\author{
Saif S. Rathore, MPH ${ }^{1}$, Jeptha P. Curtis, MD ${ }^{1}$, Brahmajee K. Nallamothu, MD, MPH ${ }^{4,5}$, Yongfei \\ Wang, MS ${ }^{1}$, JoAnne Micale Foody, MD ${ }^{1,6}$, Mikhail Kosiborod, MD ${ }^{1}$, Frederick A. Masoudi, \\ MD, MSPH $7,8,9,10$, Edward P Havranek, MD8,9,10, and Harlan M. Krumholz, MD 1,2,3,11 \\ ${ }^{1}$ Section of Cardiovascular Medicine, Department of Internal Medicine, Yale University School of \\ Medicine, New Haven, Connecticut \\ ${ }^{2}$ Section of Health Policy and Administration, Department of Epidemiology and Public Health, Yale \\ University School of Medicine, New Haven, Connecticut \\ ${ }^{3}$ Robert Wood Johnson Clinical Scholars Program, Yale University School of Medicine, New Haven, \\ Connecticut \\ ${ }^{4}$ Health Services Research and Development Center of Excellence, University of Michigan Medical \\ School, both in Ann Arbor, Michigan \\ ${ }^{5}$ Ann Arbor Veterans Administration Medical Center, and the Division of Cardiovascular Medicine, \\ Department of Internal Medicine, University of Michigan Medical School, both in Ann Arbor, \\ Michigan \\ ${ }^{6}$ West Haven Veterans Administration Medical Center, West Haven, Connecticut \\ 7 Division of Geriatric Medicine, Department of Medicine, Denver Health Medical Center, Denver, \\ Colorado \\ 8 Division of Cardiology, Department of Medicine, Denver Health Medical Center, Denver, Colorado \\ ${ }^{9}$ Colorado Foundation for Medical Care, Aurora, Colorado \\ ${ }^{10}$ Division of Cardiology, Department of Medicine, University of Colorado Health Sciences Center, \\ Denver, Colorado \\ 11 Yale-New Haven Hospital Center for Outcomes Research and Evaluation, New Haven, \\ Connecticut
}

\section{Abstract}

Current guidelines recommend ST-elevation myocardial infarction (STEMI) patients receive primary percutaneous coronary intervention (PCI) within 90 minutes of admission, although there is conflicting data regarding the relationship between time to treatment and mortality in these patients. We used logistic regression analyses employing fractional polynomial model to evaluate the association between door-to-balloon time and one-year mortality in STEMI patients age $\geq 65$ years

Corresponding author: Mr. Rathore, Room IE-61 SHM, 333 Cedar Street, PO Box 208088, New Haven, CT 06520-8088, phone (203) 737-1675, fax (203) 737-1718, saif.rathore@yale.edu.

Publisher's Disclaimer: This is a PDF file of an unedited manuscript that has been accepted for publication. As a service to our customers we are providing this early version of the manuscript. The manuscript will undergo copyediting, typesetting, and review of the resulting proof before it is published in its final citable form. Please note that during the production process errors may be discovered which could affect the content, and all legal disclaimers that apply to the journal pertain. 
undergoing primary PCI in 1994-96 ( $\mathrm{n}=1,932)$. Median door-to-balloon time was 128 minutes (interquartile range $92-178,24.2 \%$ treated within 90 minutes). Overall one-year mortality was $21.1 \%$. Longer door-to-balloon times were associated with higher one-year mortality in a continuous, nonlinear fashion (30 minutes 10.9\%, 60 minutes $13.6 \%, 90$ minutes $16.5 \%, 120$ minutes $19.5 \%$, 150 minutes $22.5 \%, 180$ minutes $25.3 \%, 210$ minutes $27.9 \%$ ). The nature of the association between door-to-balloon time and one-year mortality was best modeled by a second-degree fractional polynomial $(\mathrm{P}<0.001)$. Findings were similar after multivariable adjustment as any increase in doorto-balloon time was associated with successive increases in patients' one-year mortality (30 minutes $8.8 \%, 60$ minutes $12.9 \%, 90$ minutes $16.6 \%, 120$ minutes $19.9 \%, 150$ minutes $22.9 \%, 180$ minutes $25.5 \%, 210$ minutes $27.7 \%$ ). In conclusion, any delay in primary PCI is associated with increased one-year mortality, suggesting efforts should focus on reducing time to treatment as much as possible, even among those centers currently providing primary PCI within 90 minutes.

\section{Keywords}

primary PCI; door-to-balloon time; mortality

\section{Introduction}

Previous studies provide conflicting findings regarding the association of door-to-balloon time and mortality in patients with ST-elevation myocardial infarction undergoing primary percutaneous coronary intervention (PCI) ${ }^{1-14}$ To address this issue, we analyzed data from the Cooperative Cardiovascular Project (CCP), a database containing detailed medical record data of Medicare patients hospitalized with myocardial infarction (MI). We sought to assess the association of door-to-balloon time and mortality up to one-year after admission in a national sample of community-based patients undergoing primary PCI using statistical modeling techniques that made no assumptions regarding the nature of the association between time to treatment and mortality. We hypothesized that any increase in door-to-balloon time would be associated with increased mortality and that this mortality risk would persist irrespective of the length of the treatment delay.

\section{Methods}

The CCP, described in detail elsewhere, ${ }^{15}$ is a database of fee-for-service Medicare beneficiaries who were discharged from an acute care non-governmental hospital in the United States with a primary discharge diagnosis of acute myocardial infarction (International Classification of Diseases, Ninth Revision, Clinical Modification [ICD-9-CM] code 410) between January 1994 and February 1996, with the exception of myocardial infarction readmissions (code 410.x2). Patient records were abstracted at one of two data abstraction centers for detailed clinical information including medical history, presentation, laboratory and electrocardiographic data, in-hospital events, treatment, and discharge disposition.

We limited our analysis to the initial admission of patients 65 years of age and older who directly presented to the treating hospital within 12 hours of symptom onset with an initial electrocardiogram that showed ST segment elevation or a left bundle branch block and who subsequently underwent primary PCI $(n=3,950)$. In order to limit sample heterogeneity, we excluded 930 patients who first received fibrinolytic therapy and were subsequently referred for PCI. Of the remaining 3,020 patients, time to treatment data were missing for 1,088 patients $(36.3 \%)$, leaving a final study cohort of 1,932 patients.

Door-to-balloon time was defined as the time in minutes between a patient's arrival at the hospital and first balloon inflation as documented in the patient's medical record. For the 
purpose of evaluating differences in patient characteristics associated with time to treatment, patients were divided into five groups: $<60$ minutes, 60-119 minutes, 120-179 minutes, 180239 minutes, 240 minutes and longer. For all other analyses, door-to-balloon time was modeled as a continuous variable.

We first determined the mean, median, and distribution of time to treatment of patients in the study cohort. Differences in patient demographic and clinical characteristics were compared across the five door-to-balloon time groups using chi-square tests and trend analyses for categorical variables and analyses of variance for continuous variables.

We conducted a logistic regression analysis using fractional polynomial modeling in order to determine the specific nature of the unadjusted association between door-to-balloon time and mortality at 30 days and one-year. Fractional polynomial modeling compares models of different combinations of linear and non-linear transformations of door-to-balloon time in order to identify those models which best reflect the association of time to treatment and mortality. 16 The best fitting transformations were identified by comparison of model deviances using a chi-squared distribution on 1 degree of freedom.

Analyses were repeated adjusting for patient characteristics associated with mortality identified from previous studies, ${ }^{17}$ including patient sex, race, age, presence of angina, time from symptom onset to hospital arrival ( $<6$ hours, 6-12 hours), presentation characteristics (shock, cardiac arrest, systolic blood pressure, heart rate), electrocardiographic findings on admission (left bundle branch block, Q wave MI, sum of ST segment elevation, infarct location), and medical history (prior MI, cerebrovascular disease, congestive heart failure, chronic obstructive pulmonary disease, diabetes, hypertension, smoking history, prior coronary revascularization). Models also adjusted for the annual MI volume of the patient's treating hospital and the presence of on-site surgical backup.

To assess the robustness of our findings, we conducted two secondary analyses. We first repeated analyses excluding patients who arrived in shock because time to treatment may not be associated with mortality in patients not in shock. ${ }^{5}$ To further reduce sample heterogeneity, we repeated analyses in the cohort of patients who experienced angina and presented within 6 hours of symptom onset.

Logistic regression models accounted for clustering of patients by hospital by using HuberWhite robust estimates of standard error. ${ }^{18}$ Statistical analyses were conducted using SAS 9.1 (SAS Institute Incorporated, Cary, North Carolina) and StataSE 8.0 (Stata Corporation, College Station, Texas).

\section{Results}

Of the 3,020 patients who met criteria for inclusion, time to treatment data was available for 1,932 patients $(63.7 \%)$. Patients with missing time to treatment data $(n=1,088,36.3 \%)$ had similar mortality as the patients included in the study cohort at 30 -days (13.8\% vs. $14.4 \%$, $\mathrm{p}=0.65)$ and one-year $(21.0 \%$ vs. $21.1 \%, \mathrm{p}=0.95)$.

Median door-to-balloon time in the study cohort was 128 minutes (25th to 75th percentile, 92 minutes to 178 minutes), with 469 patients (24.3\%) treated within 90 minutes of admission (Table 1). A greater proportion of patients who had longer door-to-balloon times were women, non-white, had a higher prevalence of comorbid conditions, were more likely to arrive more than 6 hours after symptom onset, and, on average, older than patients with shorter times to treatment. There were no differences in hospital characteristics among patients with different door-to-balloon times (Table 2). 
Mortality in the study cohort was $14.4 \%$ at 30 days and $21.2 \%$ at one-year. Patients who died within 30 days had a 26 minute longer median door-to-balloon time than those patients who survived ( 150 minutes vs. 124 minutes, $\mathrm{P}<0.001)$. Similarly, patients who died within one year of admission also had a 26 minute longer median door-to-balloon time than those patients who survived the year (148 minutes vs. 122 minutes, $\mathrm{P}<0.001)$.

Logistic regression analysis using a second-degree fractional polynomial best modeled the unadjusted association of door to balloon time with 30-day mortality and one-year mortality (Figures 1A, 1B). Although the specific nature of the association between door to balloon time and mortality differed for the 2 endpoints, each indicated an increased mortality risk associated with any delay in time to treatment after admission (Table 3). Longer door to balloon times continued to be associated with increased mortality at 30 days and one year after multivariable adjustment for patient factors and hospital characteristics (Figures 2A, 2B). A second-degree fractional polynomial continued to provide the best fit for the adjusted association of door to balloon time and mortality at 30 days and one year (Table 3 ). Results were similar when analyses were repeated among patients with angina presenting within 6 hours of symptom onset and excluding patients who had presented in shock (data not shown).

\section{Discussion}

Our data indicate that delays in door-to-balloon time for patients with STEMI undergoing primary PCI are associated with increased risk of mortality at 30 days and one year. Whereas other studies have suggested that door-to-balloon time-associated mortality risks only manifest after $\geq 2$ hours of delay or otherwise plateau after longer periods of delay, our results indicate that longer door-to-balloon time are associated with an immediate increase in mortality and that this risk is present irrespective of the length of the treatment delay.

Our main finding of an increase in mortality associated with any delay in door-to-balloon time appears to reconcile competing reports regarding the specific nature of the mortality risk associated with delays in time to treatment. ${ }^{1-14}$ Our study suggests that the mortality risk associated with any delay in time to treatment may be both present immediately after admission and persist for several hours. A closer assessment of prior studies indicates that many in fact suggest such a consistent trend of increased mortality with any delay in time to treatment. For instance, although Cannon and colleagues report that mortality associated with longer doorto-balloon times was only present after two or more hours of delay, there is a clear trend towards increased mortality in patients with door-to-balloon times of 61 to 90 minutes and 91 to 120 minutes. ${ }^{14}$

Our finding of an increased mortality risk associated with delayed time to treatment in patients undergoing primary PCI is consistent with current pathophysiological models of myocardial infarction. ${ }^{19}$ Experimental models have demonstrated that the continuous, progressive 'wave front of necrosis' is largely dependent upon the duration of ischemia. Thus, patients with longer door-to-balloon times will experience, on average, longer periods of vessel occlusion, resulting in more ischemia and greater necrosis than patients with shorter times to treatment. This is reflected in poorer intermediate measures of myocardial viability including decreased myocardial perfusion, smaller ST segment resolution, less myocardial salvage and diminished left ventricular function. ${ }^{20}$

We believe our study's finding that every minute of delay in treatment is associated with an increased risk of one-year mortality has important implications for clinical practice. Notably, efforts to further reduce door to balloon times, even below the 90 minute benchmark currently recommended by clinical practice guidelines,${ }^{21}$ offer the potential to significantly reduce patient mortality. For instance, our data suggest that reducing average time to treatment from 
90 minutes to 60 minutes may reduce one-year mortality by as much as $3.7 \%$ (16.6\% to $12.9 \%$ ). A further 30 minute reduction in average time to treatment to 30 minutes offers the potential of an additional $4.1 \%$ reduction (12.9\% to $8.1 \%$ ) in one-year mortality, underscoring the nonlinear relationship between time to treatment and mortality. Rather than accepting a 90 minute door to balloon time benchmark for primary PCI, our data suggest we instead adopt an 'as soon as possible' standard for patients undergoing primary PCI.

Our study has several limitations that merit consideration. First, we were unable to assess the association of time from symptom onset to hospital arrival and mortality or the association of total ischemic time to mortality. We attempted to limit this effect by conducting a secondary analysis restricted to patients who presented within 6 hours of symptom onset and found our results were similar. Further, robust assessment of time from symptom onset to hospital admission may be problematic in that these times necessarily rely on patient report and thus cannot be independently verified, whereas door to balloon times are likely more accurately recorded. Second, 1,088 patients eligible for inclusion in the study cohort were excluded due to lack of time to treatment data. However, similarity of 30-day and one-year mortality rates in this group of patients with those patients with available time to treatment data suggests no apparent selection bias. Third, our analysis is based on patients treated between 1994 and 1996 and thus may not reflect newer technologies, including use of stents and glycoprotein IIb/IIIa inhibitors. However, stents and glycoprotein IIb/IIIa inhibitors have not been demonstrated to reduce mortality in patients undergoing primary PCI ${ }^{22,23}$ Fifth, our analysis was based on a non-randomized observational cohort design, thus our findings may be attributable to biases introduced by unmeasured factors. Finally, the CCP database consisted of elderly patients, and thus our findings may not be generalizable to younger patients undergoing primary PCI for STEMI. However, characterizing the association of time to treatment and mortality for elderly patients receiving primary PCI may be beneficial because of their increased risk for delays in time to treatment. ${ }^{24}$

\section{Acknowledgments}

Mr. Rathore is supported by NIH Medical Scientist Training Grant GM07205. Dr. Nallamothu is supported as a clinical scholar under a K12 grant from the NIH (RR017607-01). Dr. Foody is supported by National Institute on Aging (NIA) Research Career Award K08-AG20623-01 and a NIA/Hartford Foundation Fellowship in Geriatrics. Dr. Masoudi is supported by NIA Research Career Award K08-AG01011. This research was supported by grant R01 HL072575 of the National Heart, Lung, and Blood Institute.

The analyses upon which this publication is based were performed under Contract Number 500-02-CO-01, entitled, "Utilization and Quality Control Peer Review Organization for the State of Colorado," sponsored by the Centers for Medicare \& Medicaid Services (CMS, formerly the Health Care Financing Administration), U.S. Department of Health and Human Services. The content of this publication does not necessarily reflect the views or policies of the U.S. Department of Health and Human Services, nor does mention of trade names, commercial products, or organization imply endorsement by the U.S. Government. The author assumes full responsibility for the accuracy and completeness of the ideas presented. This article is a direct result of the Health Care Quality Improvement Program initiated by the Health Care Financing Administration, which has encouraged identification of quality improvement projects derived from analysis of patterns of care, and therefore required no special funding on the part of this Contractor. Ideas and contributions to the author concerning experience in engaging with issues presented are welcomed.

\section{References}

1. De Luca G, Suryapranata H, Zijlstra F, van't Hof AWJ, Hoorntje JCA, Gosselink ATM, Dambrink J, de Boer M-J. on behalf of the Zwolle Myocardial Infarction Study. Symptom-onset-to-ballon time and mortality in patients with acute myocardial infarction treated by primary angioplasty. J Am Coll Cardiol 2003;42:991-997. [PubMed: 13678918]

2. Antoniucci D, Valenti R, Migliorini A, Moschi G, Trapani M, Buonamici P, Cerisano G, Bolognese L, Santoro GM. Relation of time to treatment and mortality in patients with acute myocardial infarction undergoing primary coronary angioplasty. Am J Cardiol 2002;89:1248-1252. [PubMed: 12031722] 
3. Schomig A, Ndrepepa G, Mehilli J, Schwaiger M, Schulen H, Nekolla S, Pache J, Martinoff S, Bollwein $\mathrm{H}$, Kastrati A. Therapy-dependent influence of time-to-treatment interval on myocardial salvage in patients with acute myocardial infarction treated with coronary artery stenting or thrombolysis. Circulation 2003;108:1084-1088. [PubMed: 12925458]

4. Brodie BR, Stone GW, Morice M-C, Cox DA, Garcia E, Mattos LA, Boura J, O'Neill WW, Stuckey TD, Milks S, Lansky AJ, Grines CL. for the Stent Primary Angioplasty in Myocardial Infarction Study Group. Importance of time to reperfusion on outcomes with primary coronary angioplasty for acute myocardial infarction. Am J Cardiol 2001;188:1085-1090. [PubMed: 11703949]

5. Brodie BR, Stuckey TD, Muncy DB, Hansen CJ, Wall TC, Pulsipher M, Gupta N. Importance of timeto-reperfusion in patients with acute myocardial infarction with and without cardiogenic shock treated with primary percutaneous coronary intervention. Am Heart J 2003;145:708-715. [PubMed: 12679769]

6. De Luca G, Suryapranata H, Ottervanger JP, Antman EM. Time delay to treatment and mortality in primary angioplasty for acute myocardial infarction: every minute of delay counts. Circulation 2004;109:1223-1225. [PubMed: 15007008]

7. De Luca G, van't Hof AWJ, de Boer M-J, Ottervanger JP, Hoorntje JCA, Gosselink ATM, Dambrink JE, Zijlstra F, Suryapranata H. Time-to-treatment significantly affects the extent of ST-segment blush resolution and myocardial blush in patients with acute myocardial infarction treated by primary angioplasty. Eur Heart J 2004;25:1009-1013. [PubMed: 15191770]

8. Berger PB, Ellis SG, Holmes DRJ, Granger CB, Criger DA, Betriu A, Topol EJ, Califf RM. for the GUSTO-II Investigators. Relationship between delay in performing direct coronary angioplasty and early clinical outcome in patients with acute myocardial infarction. Circulation 1999;100:14-20. [PubMed: 10393675]

9. van't Hof AWJ, Liem A, Suryapranata H, Hoorntje JCA, de Boer M-J, Zijlstra F. Clinical presentation and outcome of patients with early, intermediate, and late reperfusion therapy by primary coronary angioplasty for acute myocardial infarction. Eur Heart J 1998;19:118-123. [PubMed: 9503184]

10. McNamara RL, Wang Y, Herrin J, Curtis JP, Bradley EH, Magid DJ, Peterson ED, Blaney M, Frederick PD, Krumholz HM. for the NRMI Investigators. Effect of door-to-balloon time on mortality in patients with ST-segment elevation myocardial infarction. J Am Coll Cardiol 2006;47:2180-2186. [PubMed: 16750682]

11. Stone GW, O’Keefe J, Brodie BR, O’Neill WW, Grines CL. Lack of relationship between the time to reperfusion and short-term mortality after primary infarct angioplasty [abstract]. J Am Coll Cardiol 1998;31:271A.

12. Brodie BR, Stuckey TD, Wall TC, Kissling G, Hansen CJ, Muncy DB, Weintraub RA, Kelly TA. Importance of time to reperfusion for 30-day and late survival and recovery of left ventricular function after primary angioplasty for acute myocardial infarction. J Am Coll Cardiol 1998;32:1312-1319. [PubMed: 9809941]

13. Juliard J-M, Feldman LJ, Golmard J-L, Himbert D, Benamer H, Haghighat T, Karila-Cohen D, Aubry P, Vahanian A, Steg PG. Relation of mortality of primary angioplasty during acute myocardial infarction to door-to-Thrombolysis in Myocardial Infarction (TIMI) time. Am J Cardiol 2003;91:1401-1405. [PubMed: 12804723]

14. Cannon CP, Gibson CM, Lambrew CT, Shoultz DA, Levy D, French WJ, Gore JM, Weaver WD, Rogers WJ, Tiefenbrunn AJ. Relationship of symptom-onset-to-balloon time and door-to-balloon time with mortality in patients undergoing angioplasty for acute myocardial infarction. JAMA 2000;283:2941-2947. [PubMed: 10865271]

15. Marciniak TA, Ellerbeck EF, Radford MJ, Kresowik TF, Gold JA, Krumholz HM, Kiefe CI, Allman RM, Vogel RA, Jencks SF. Improving the quality of care for Medicare patients with acute myocardial infarction. Results from the Cooperative Cardiovascular Project. JAMA 1998;279:1351-7. [PubMed: 9582042]

16. Royston P, Ambler G, Saurbrei W. The use of fractional polynomials to model continuous risk variables in epidemiology. Intl J Epidemiol 1999;28:964-974.

17. Chen J, Rathore SS, Radford MJ, Wang Y, Krumholz HM. Racial differences in the use of cardiac catheterization after acute myocardial infarction. N Engl J Med 2001;344:1443-1449. [PubMed: 11346810] 
18. White HA. A heteroskedasticity-consistent covariance matrix estimator and a direct test for heteroskedasticity. Econometrica 1980;48:817-838.

19. Reimer KA, Lowe JE, Rasmussen MM, Jennings RB. The wavefront phenomenon of ischemic cell death: myocardial infarct size vs. duration of coronary occlusion in dogs. Circulation 1977;56:786794. [PubMed: 912839]

20. Milavetz JJ, Giebel DW, Christian TF, Schwartz RS, Holmes DRJ, Gibbons RJ. Time to therapy and salvage in myocardial infarction. J Am Coll Cardiol 1998;31:1246-1251. [PubMed: 9581715]

21. Antman EM, Hand M, Armstrong PW, Bates ER, Green LA, Halasyamani LK, Hochman JS, Krumholz HM, Lamas GA, Mullany CJ, Pearle DL, Sloan MA, Smith SCJ. 2007 focused updated of the ACC/AHA 2004 guidelines for the management of patients with ST-elevation myocardial infarction: a report of the American College of Cardiology/American Heart Association Task Force on Practice Guidelines (Writing Group to Review New Evidence and Update the ACC/AHA 2004 Guidelines for the Management of Patients with ST-Elevation Myocardial Infarction). J Am Coll Cardiol 2008;151:210-247. [PubMed: 18191746]

22. Grines CL, Cox DA, Stone GW, Garcia E, Mattos LA, Giambartolomei A, Brodie BR, Madonna O, Eijgelshoven M, Lansky AJ, O’Neill WW, Morice M-C. Coronary angioplasty with or without stent implantation for acute myocardial infarction: the Stent Primary Angioplasty in Myocardial Infarction Study Group. N Engl J Med 1999;341:1949-1956. [PubMed: 10607811]

23. Montalescot G, Barragan P, Wittenberg O, Ecollan P, Elhadad S, Villain P, Boulenc J-M, Morice MC, Maillard L, Pansieri M, Choussat R, Pinton P. for the ADMIRAL Investigators. Platelet glycoprotein IIb/IIIa inhibition with coronary stenting for acute myocardial infarction. N Engl J Med 2001;344:1895-1903. [PubMed: 11419426]

24. Angeja BG, Gibson CM, Chin R, Frederick PD, Every NR, Ross AM, Stone GW, Barron HV. for the National Registry of Myocardial Infarction 2 Investigators. Predictors of door-to-balloon delay in primary angioplasty. Am J Cardiol 2002;89:1156-1161. [PubMed: 12008167] 


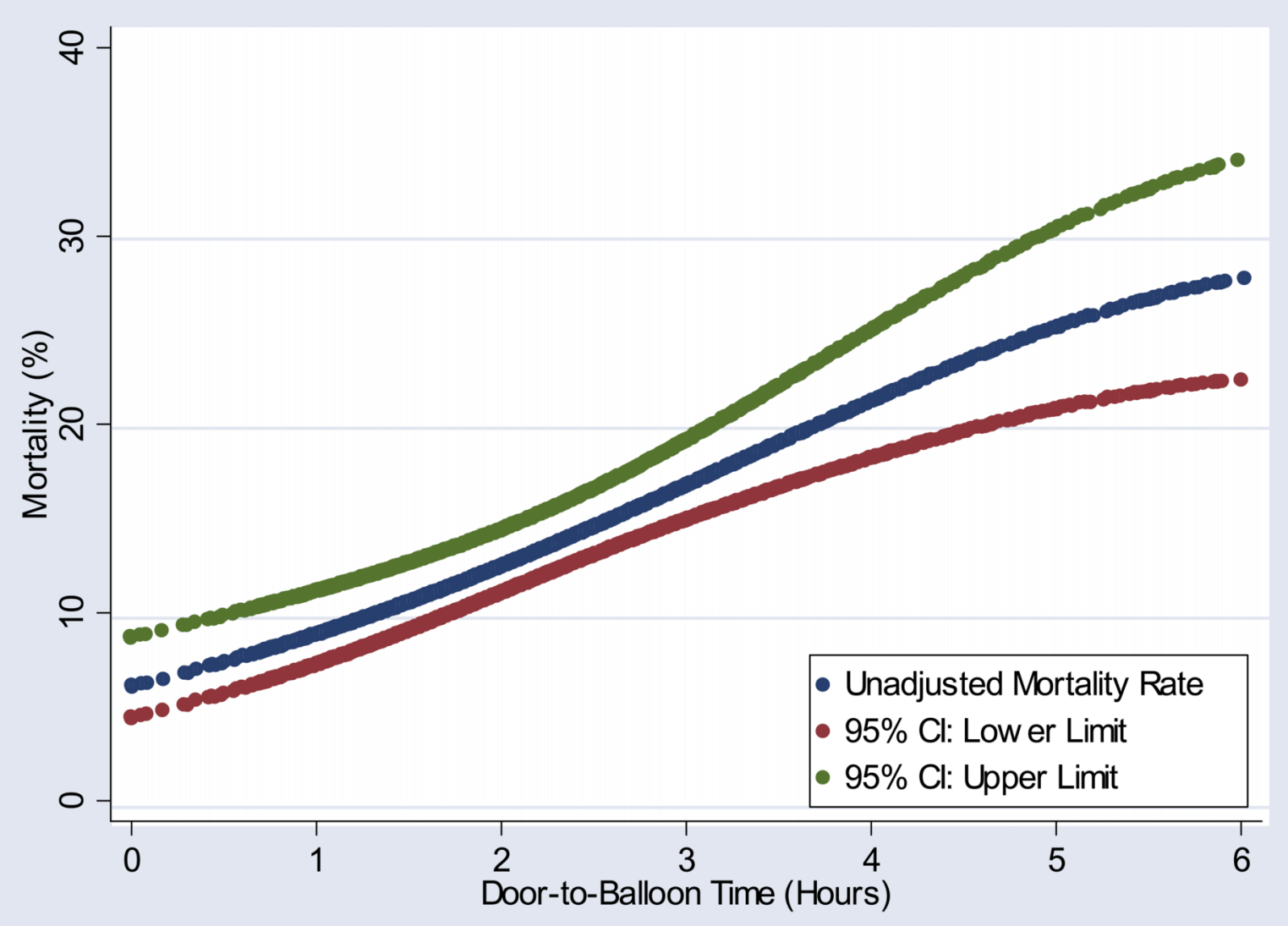




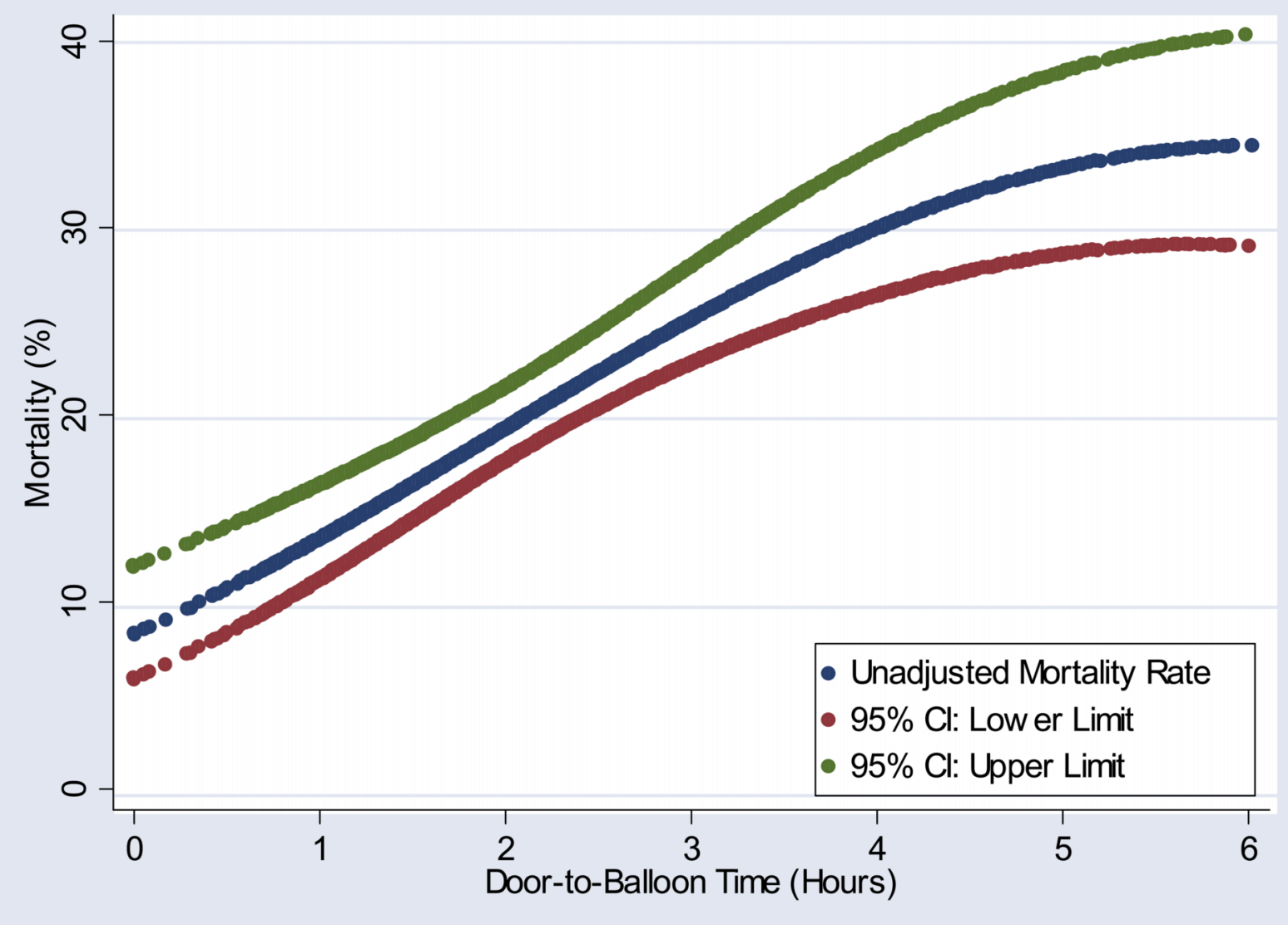

Figure 1.

Figure 1A. Unadjusted association of door-to-balloon time and 30-day mortality Figure 1B. Unadjusted association of door-to-balloon time and one-year mortality 


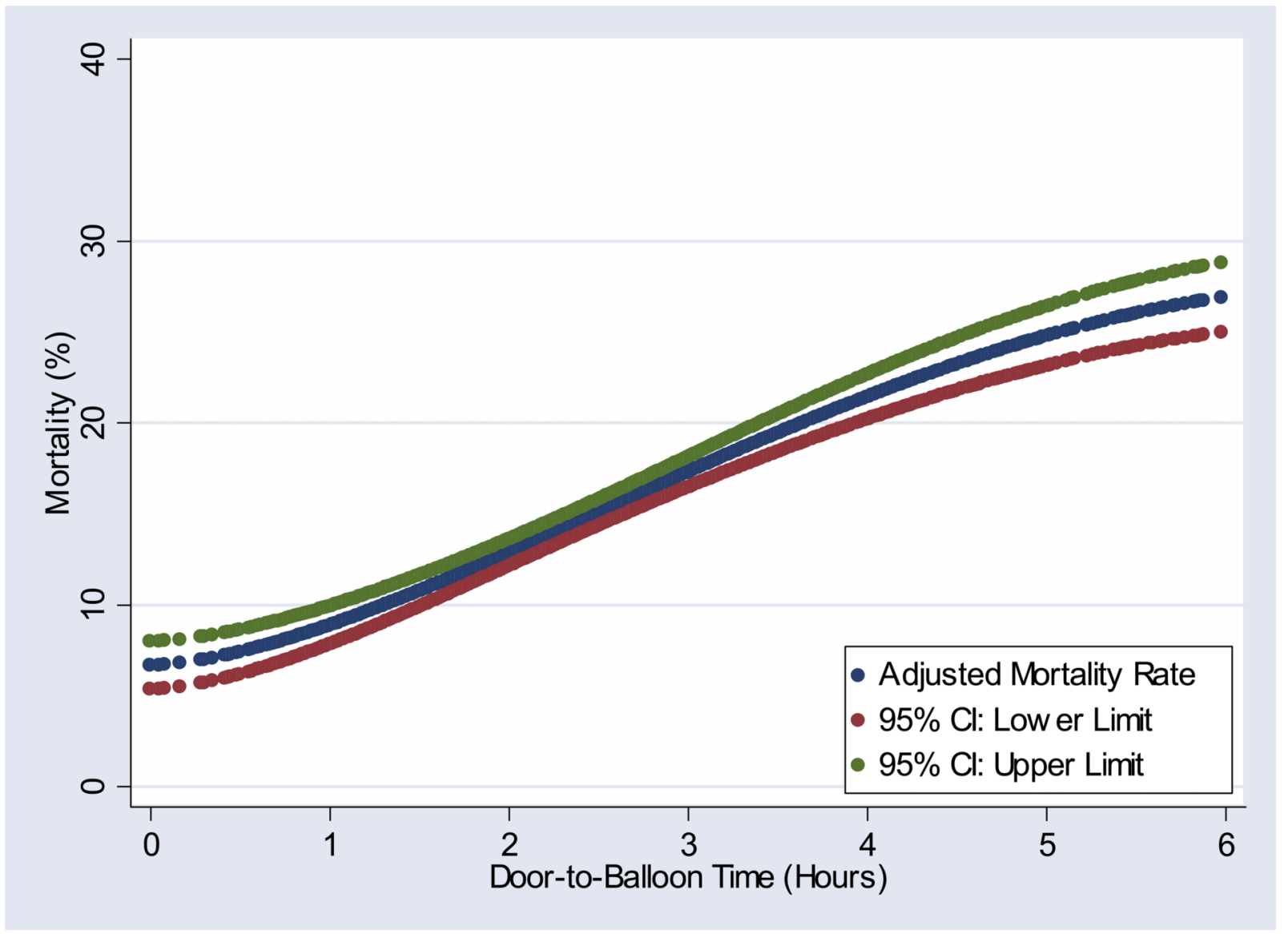




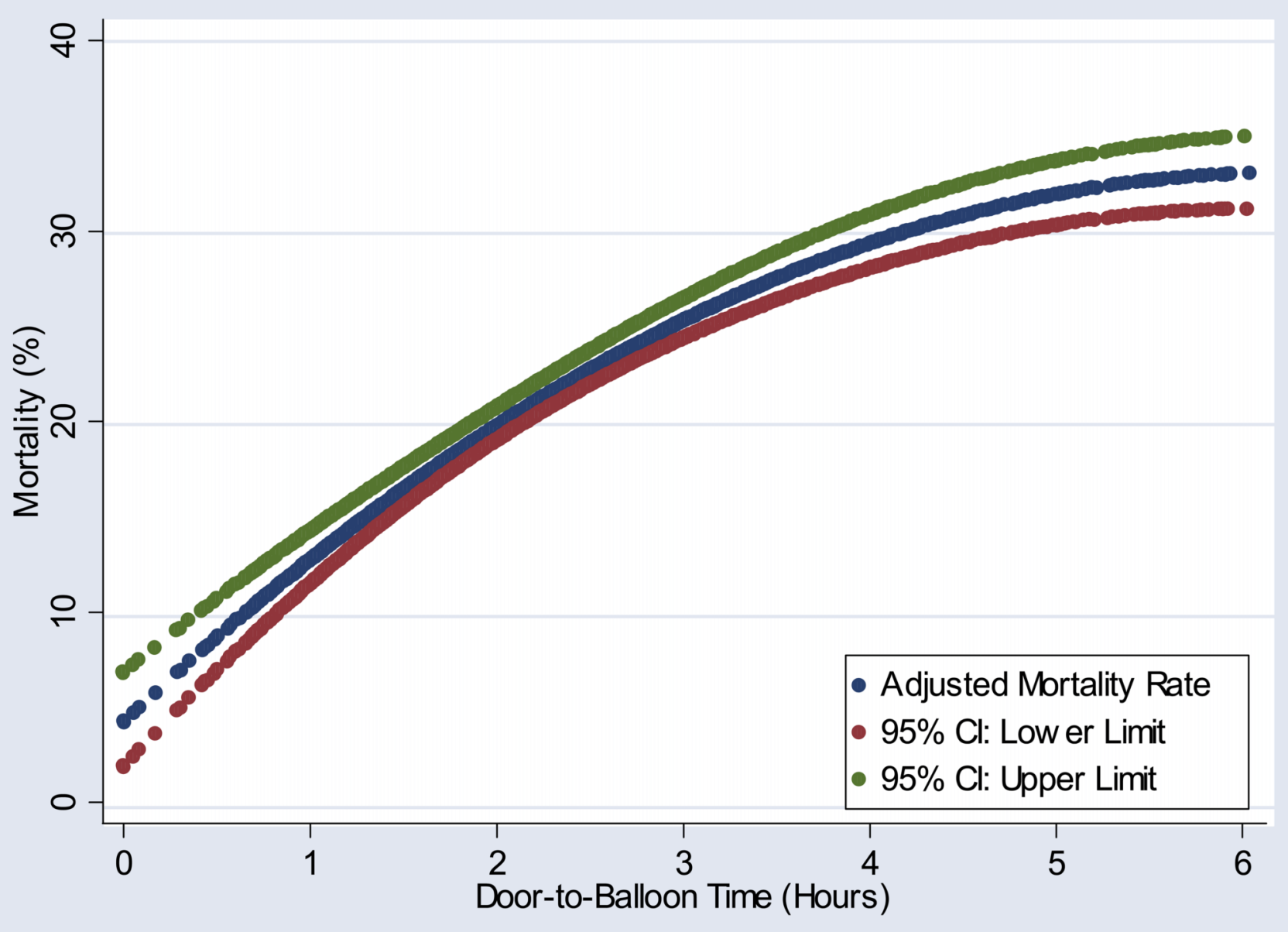

Figure 2.

Figure 2A. Adjusted association of door-to-balloon time and 30-day mortality Figure 2B. Adjusted association of door-to-balloon time and one-year mortality 
Table 1

Distribution of door-to-balloon time $(\mathrm{n}=1932)$

\begin{tabular}{lc}
\hline Time (minutes) & N (proportion of cohort) \\
\hline$\leq 30$ & $15(0.8 \%)$ \\
$31-60$ & $96(5.0 \%)$ \\
$61-90$ & $358(18.5 \%)$ \\
$91-120$ & $400(20.7 \%)$ \\
$121-150$ & $372(19.2 \%)$ \\
$151-180$ & $227(11.8 \%)$ \\
$181-210$ & $146(7.6 \%)$ \\
$211-240$ & $78(4.0 \%)$ \\
$\geq 241$ & $240(12.4 \%)$ \\
\hline
\end{tabular}




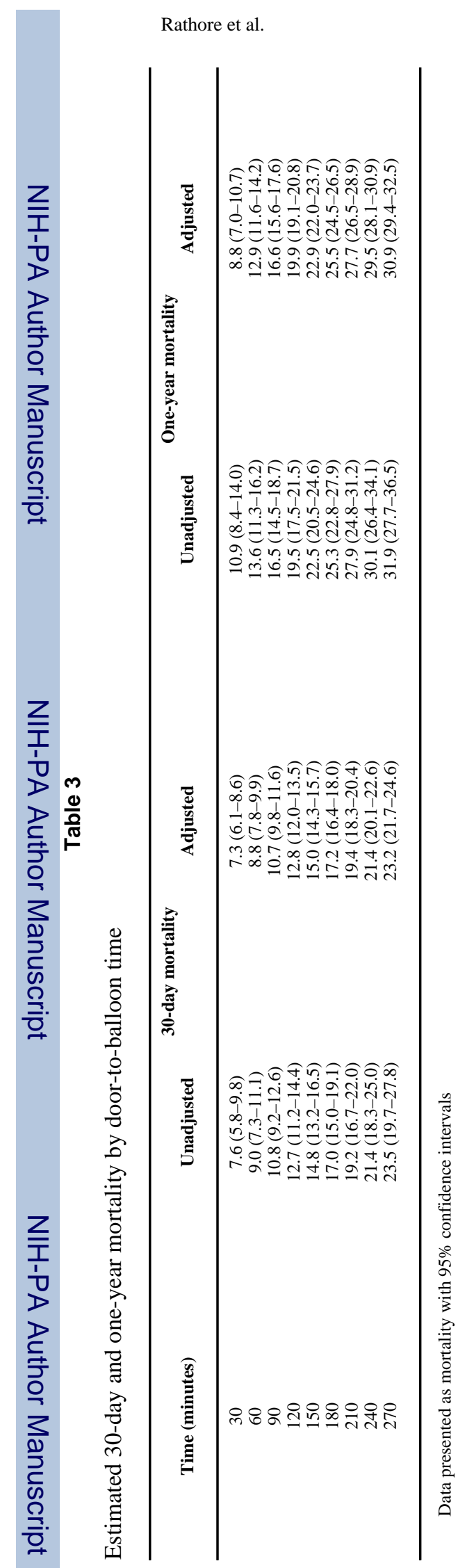

Page 14 